\title{
Opportunities of computer-aided building energy consumption design
}

\author{
Emese Sarvajcz-Bánóczy \\ Electrical Engineering and Mechatronics Department \\ University of Debrecen, Faculty of Engineering \\ Debrecen, Hungary \\ emese.banoczy@eng.unideb.hu
}

\author{
Dr. Péter Tamás Szemes, PhD \\ Electrical Engineering and Mechatronics Department \\ University of Debrecen, Faculty of Engineering \\ Debrecen, Hungary \\ szemespeter@eng.unideb.hu
}

\begin{abstract}
Nowadays a significant part of energy is consumed in buildings. In order to reduce the energy consumption different retrofit technologies are applied. As every building and every energy consumer is different the same modernization technic can not be used for all buildings. This paper shows a computer aided opportunity which is able to simulate different modernization technic for the same building in order to the best opportunity can be selected. The paper highlights the advantages of computeraided building design and the opportunities of optimization techniques in a new under design building case. This paper also contains examples in order to introduce this modelling method.
\end{abstract}

Keywords- building energetic; modernization direction; building simulation; EnergyPlus; op-timization; simulation-based; energy consumption

\section{INTRODUCTION}

Nowadays, the building sector is a remarkable energy consumer. There are many aspirations in order to reduce the energy demand in buildings, taking into consideration the growing energy demand trend. Generally is true the fact that building's energy consumption is closely linked the age of the building. In Europe nearly $40 \%$ of the buildings were constructed before 1960s. $45 \%$ of the buildings were built between 1960 and 1990, and only less than $20 \%$ of the buildings were constructed after 1990 [1]. In Hungary this fact is specially true, the buildings are old, and the remarkable part of the buildings were constructed before 1980s [2]. These elderly buildings without their retrofit do not harmonize to the actually valid building energy regulation, regarding the building envelope and the building engineering system.

Nowadays, people common select the following energy retrofit alternatives in case of existing buildings:

- window replacement

- additional external wall insulation

- heating system modernization

- application of renewable energy sources for heatingand domestic hot water systems

In Hungary until 2011 there were similar types building retrofits. The most common used retrofit was the additional external wall insulation (23\%), the second was the window replacement $(21 \%)$, and the last was the heating system modernization (13\%). $43 \%$ of the residential building there were not any kind of building modernization [2].

There are proposals to create national building typology. For example the TABULA-EPISCOPE project. In this project the typology based on the age, size and type of the residential buildings. The modelling of building types is based on theoretical calculations. For the calculations supposed that building structures have not been retrofitted since construction. The project examines two retrofit variations with theoretical calculations. The first retrofit variation is a standard refurbishment which based on the current standards. It contains $5 \mathrm{~cm}$ external insulation on existing wall structure, additional $12 \mathrm{~cm}$ external insulation on top of the existing structure, window replacement and a new condensing boiler. The other one is an ambitious refurbishment which based on the net zero building standard. It contains additional $16 \mathrm{~cm}$ external insulation of the existing wall structure, additional 28 $\mathrm{cm}$ external insulation on top of the existing structure, window replacement and condensing boiler with solar thermal system [8].

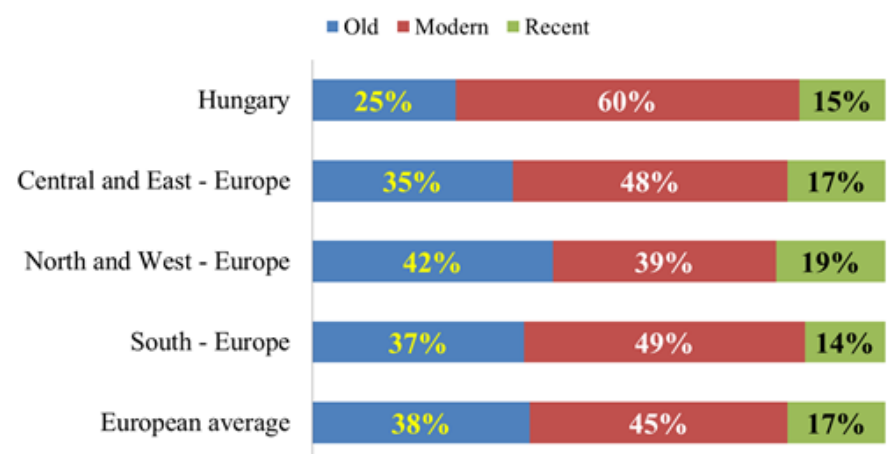

Fig.1. Age of buildings [1]

\section{Methodology}

In the focus of this research is the energy consumption of different type buildings and their economic application with particular emphasis on the construction, the elements of building engineering, the different type of heat and electric 
loads and the location and orientation of buildings and facilities. The aim of the research is producing a simulationbased building energy consumption design, which operates automatically considering the above mentioned parameters.

\section{A. Modeling building energy consumption}

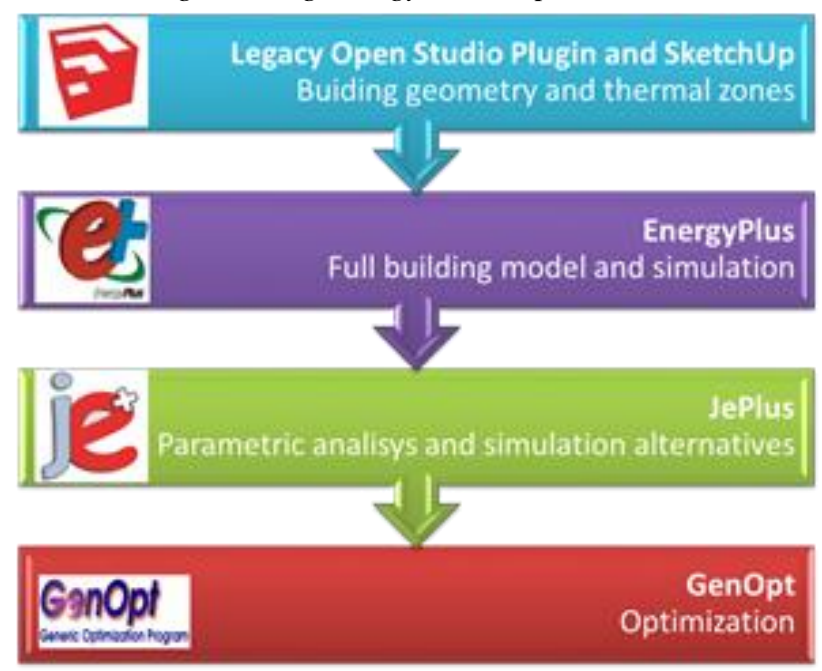

Fig.2. The developed methology of building modelling

During the process the first step is preparing geometry model of the examined building. The next step is preparation of full building model. Full building model's preparation means the adjustment of the materials, the construction, the heating-, ventilation-, and air-conditioning system, the schedules, and the different loads.

Then, depending on the building is only a plan or it is existing, the process can be examined according two cases. The first one is the examination of existing buildings; the second one is the investigation of under design buildings. Next, in the first case the existing building is examined along energy retrofit directions in order to find the best modernization solutions, in the other case the under design building is tested along design directions in order to find the best concept of the building.

In the research the base building models are created using SketchUp Make software and Legacy Open Studio Plug-in for SketchUp and EnergyPlus. Based on these parameters several different full building models can be prepared using JePlus software based on the following parameters: location, orientation, sizes of building, materials of building's construction, shape of building, shape of the roof, type of the cooling system, type of the heating system and usage of renewable energy sources, etc. [3][4][5][6][7].

According to the developed methodology the optimization process can be separated into two parts. The first one is when the aim is designed a new, economical building. In this case many directions can be selected. The other type is when the aim is generally reducing energy consumption and costs in existing buildings. In this case the numbers of opportunities are decreased, because there are parameters which cannot modify, e.g. the orientation and the evolving of the building. But in this case there are good possibilities in modernizations in construction elements (e.g. roof insulation, floor insulation, wall insulation, fenestration replacement, etc.) and in building energy systems modernization or replacements. Obviously in both cases the stop condition of the optimization is needed to be some type of financial unit, such as price-value ratio or concrete amount of money, in order to the best decision.

\section{B. Examined cases}

During this research in the focus of the authors' examination are three cases. First of all, the validation of applied simulation software is the aim. This way a family house was examined. Then a well-known type of residential houses, the „Kádár-cube” some modernization opportunities were tested. And finally, different wall structures were examined in a fictional „L-shape” building case.

The first examined case is the exactness of the EnergyPlus. During the EnergyPlus validation the authors examined a family house, which was constructed in 2004. In this case every data is available, about the building geometry, construction materials, the consumer habits, the heating- and domestic hot water systems, and also the energy consumption data. In this way the building model can be prepared and the results of the simulation can be verified.

In the building model among more other things the authors take into consideration the main materials of the wall structure, which consists of plaster $(2 \mathrm{~cm})$, polystyrene insulation, $(3 \mathrm{~cm})$, B30 walling block $(30 \mathrm{~cm})$, plaster $(1,5$ $\mathrm{cm})$. The heating and domestic hot water is supplied Saunier Duval SD 30KLZ combi gas boiler. The schedules which are an important part of the simulation are set for electric equipment, lights, temperature, resident people, etc. The schedules are based on an average Hungarian working family's daily routine, assuming on weekdays nobody is at home between 7:30 am and $5 \mathrm{pm}$, and on weekends the entire family is at home.

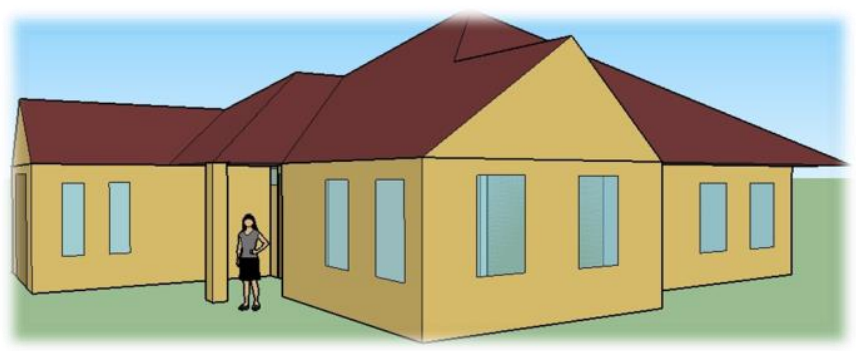

Fig. 3. The geometry model of the examined building

The second examined case is an examination of „Kádárcube" different scenarios. This type's typically construction time is between 1945-1979. The most common used wall structure in this case was the following: plaster $(1.5 \mathrm{~cm})$; solid brick wall $(38 \mathrm{~cm}$ or $25 \mathrm{~cm})$; plaster $(3 \mathrm{~cm})$. The most common used window was the box-type wooden window with single glazing, and the applied heating system was generally constant temperature non-condensing boiler. In this examination the 
authors simulated and tested six different scenarios. Table 1. shows these scenarios, among the original state as V6. During the examination the consumer habits are adjusted as a typical Hungarian family, it means that the family consists of four members.

TABLE 1. SCENARIOS OF,KÁDÁR-CUBE”MODERNIZATION

\begin{tabular}{|c|c|c|}
\hline Version & U-factor $\left[\mathbf{W} / \mathbf{m}^{\mathbf{2}} \mathbf{K}\right]$ & Insulation thickness [m] \\
\hline V1 & 1.6 & 0 \\
\hline V2 & 1 & 0 \\
\hline V3 & 2 & 0 \\
\hline V4 & 3 & 0.05 \\
\hline V5 & 3 & 0.2 \\
\hline V6 & 3 & 0 \\
\hline
\end{tabular}

The third examined case is investigation of different wall structures for the same L-shape building, while the other parameters are constant. During this examination the authors tested different materials as solid brick, B30 brick, Ytong block and different wall and insulation thickness. In this way twenty variations are examined as shown in Table 2.

TABLE 2. L-SHAPE BUILDING'S DIFFERENT WALL STRUCTURE

\begin{tabular}{|c|c|c|c|}
\hline Version & Wall type & $\begin{array}{c}\text { Wall } \\
\text { thickness [m] }\end{array}$ & $\begin{array}{c}\text { Insulation } \\
\text { thickness [m] }\end{array}$ \\
\hline V1 & Solid brick wall & 0.25 & 0 \\
\hline $\mathrm{V} 2$ & Solid brick wall & 0.38 & 0 \\
\hline V3 & Solid brick wall & 0.25 & 0.05 \\
\hline V4 & Solid brick wall & 0.38 & 0.05 \\
\hline V5 & Solid brick wall & 0.25 & 0.1 \\
\hline V6 & Solid brick wall & 0.38 & 0.1 \\
\hline V7 & Solid brick wall & 0.25 & 0.2 \\
\hline V8 & Solid brick wall & 0.38 & 0.2 \\
\hline V9 & B30 brick wall & 0.3 & 0 \\
\hline V10 & B30 brick wall & 0.3 & 0.05 \\
\hline V11 & B30 brick wall & 0.3 & 0.16 \\
\hline V12 & B30 brick wall & 0.3 & 0.2 \\
\hline V13 & Ytong block wall & 0.3 & 0 \\
\hline V14 & Ytong block wall & 0.3 & 0.05 \\
\hline V15 & Ytong block wall & 0.3 & 0.16 \\
\hline V16 & Ytong block wall & 0.3 & 0.2 \\
\hline V17 & Solid brick wall & 0.51 & 0 \\
\hline V18 & Solid brick wall & 0.51 & 0.05 \\
\hline V19 & Solid brick wall & 0.51 & 0.1 \\
\hline V20 & Solid brick wall & 0.51 & 0.2 \\
\hline
\end{tabular}

\section{RESULTS}

In this part the authors introduce the results of the three examined cases. First of all the validation results of the EnergyPlus software are introduced. Then the „Kádár-cube” scenario's simulation results are summarized, and finally the optimal wall structure's simulation results are introduced.

\section{A. EnergyPlus validation}

Table 3. shows the results of comparison of the simulated and measured data. According to the Table 3 can be determined that the simulation approximate well the real data. Differences can originate from the following combined effect of different parameters:

- The measured data is average value from the last 10 years

- The weather file, which needed for the simulation process is based on several years' average data, while the weather is constantly changing.

- Sometimes the real schedules can differ from the average one, when the occupier according to the schedules is not home, however the occupier is at home because any reason e.g. in case of illness, holidays, etc

TABLE 3. COMPARISON OF THE SIMULATED AND MEASURED DATA

\begin{tabular}{|c|c|c|}
\hline Examined data & $\begin{array}{c}\text { Simulated } \\
\text { data }\end{array}$ & $\begin{array}{c}\text { Average measured } \\
\text { data in last 10 year }\end{array}$ \\
\hline Gas consumption [GJ] & 93.29 & 95.10 \\
\hline Electricity consumption $[\mathrm{GJ}]$ & 12.1 & 10.8 \\
\hline $\begin{array}{c}\text { Domestic water consumption } \\
{\left[\mathrm{m}^{3}\right]}\end{array}$ & 126.14 & 120 \\
\hline
\end{tabular}

\section{B. „Kádár-cube” scenarios}

During this case the authors examined some modernization opportunity of the typical Hungarian residential building, which called „Kádár-cube”. It can be determined the fact that the modernization of this old type building means excellent opportunities in order to reduce the energy consumption. Figure 4. shows the results of the examined modernization scenarios. V6 means the originale state of this building type. During the examination in every scenario only one parameter was modified. It means that only the additional external insulation or only the window replacement was tested. In this way it can be determined that the best scenario of the examined opportunities is V5 scenario, which means $0.2 \mathrm{~m}$ additional external insulation. Then comes V4 scenario, which also means additional external insulation, and only after them followed by the window replacement as modernization techniq. 


\section{Examination of L-shape building optimal wall structure}

In this case different type wall structure was investigated in order to the most optimal opportunity can be selected. It can be useful in a new, under design building case.

Figure 5. shows the results of the simulated opportunities. According to the results can be determined the fact that the Ytong block wall with any kind and size of insulation means the most optimal solution. Investigating the different types wall structure can be diagnosed that the wall thickness
Based on this study can be determined the statement that the material of the wall structure and the insulation thickness have more significant impact on the energy consumption (mainly the heating energy) than the thickness of the walling block

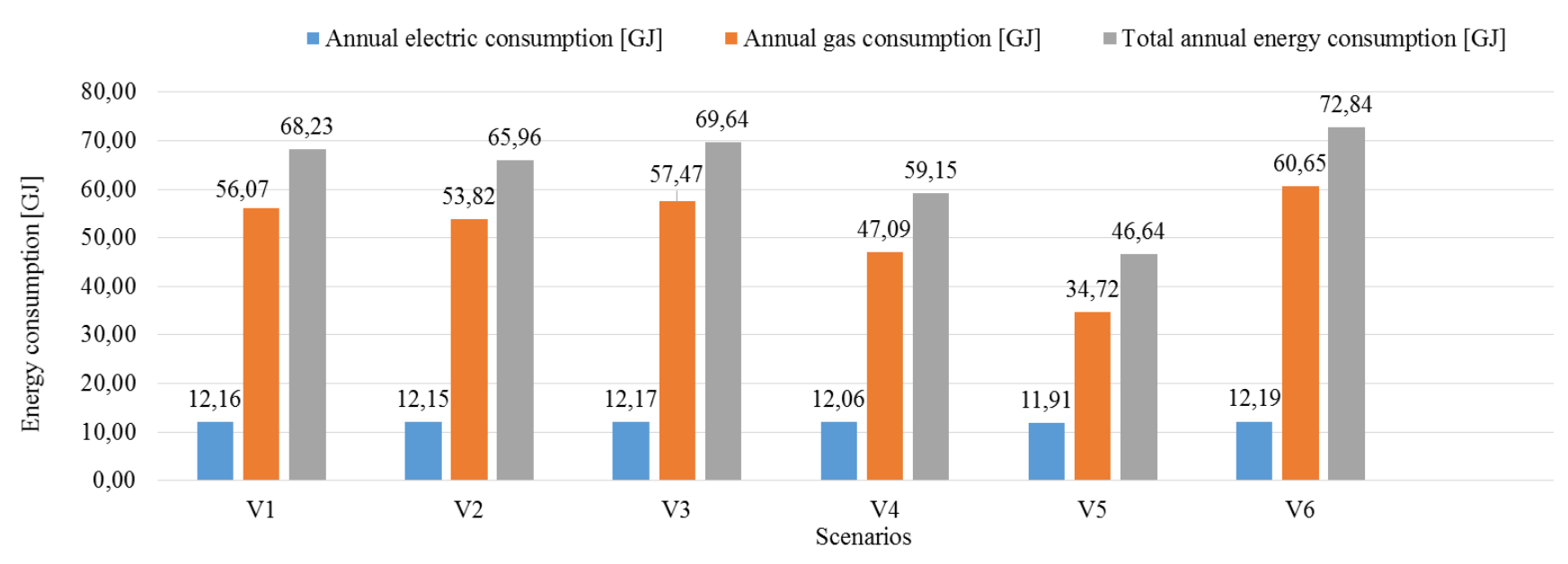

Fig.4. Comparison of different scenarios

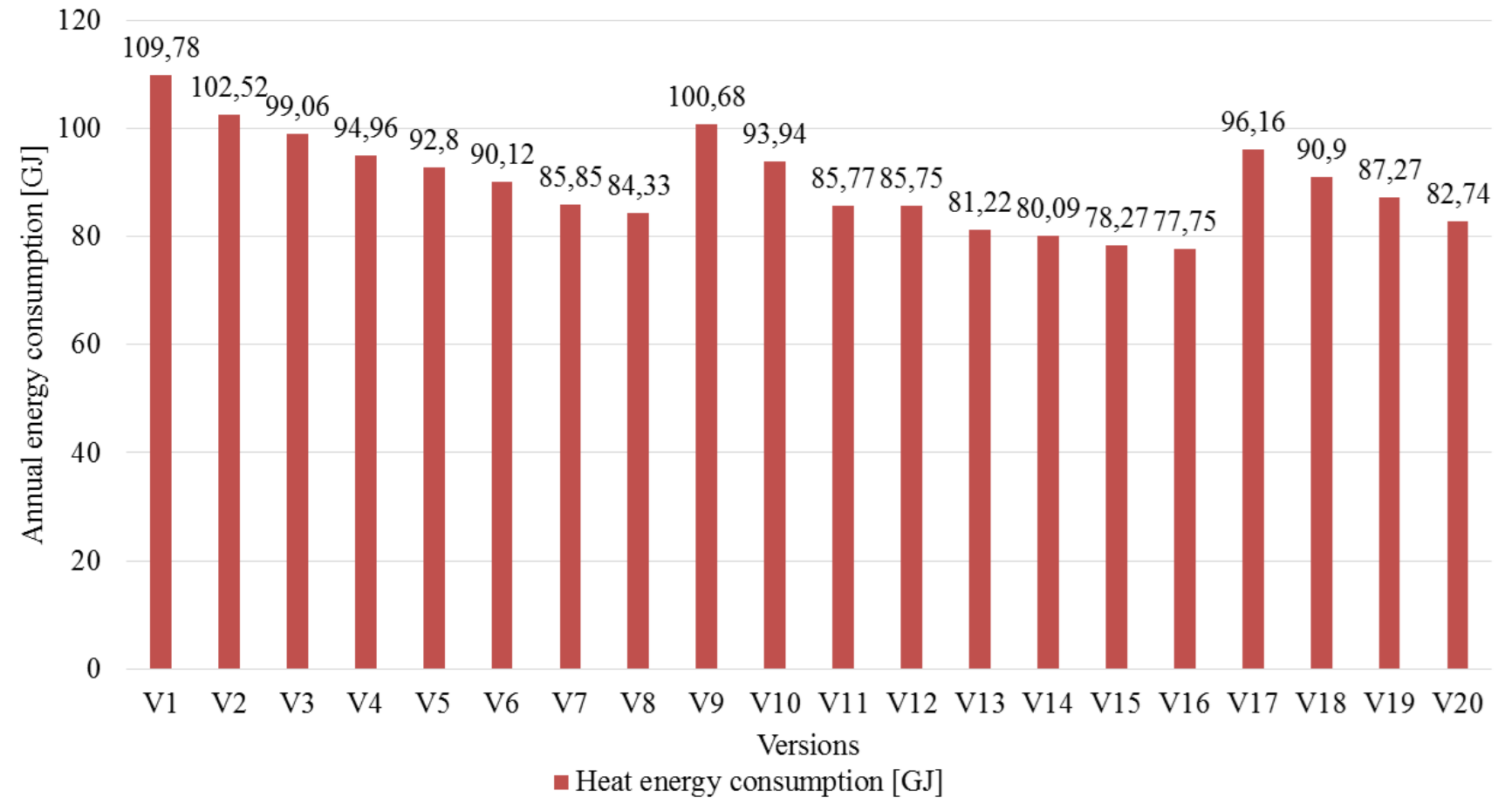

Fig.5. Examination of different type wall structure 


\section{CONCLUSION AND FUTURE WORKS}

Because of the heterogeneity of the building sector in Hungary and in Europe too, creating a building typology is very difficult. It needed to take into consideration of many facts and impacts in order to obtain correct and valid energy consumption results. The importance of computer-aided building energy consumption design is certified because the above mention facts.

The computer-aided building energy consumption design provides an opportunity to get an objective picture about an existing building. It can be useful in tenders, when objectivity is necessary. Furthermore, it is employable in cases of different retrofit opportunities to select the most optimal possibility. It is useful to design a new sustainable building with economical operation. And it works effective to design an affordable building which performs low energy buildings requirement and can obtain building permit from 2020 . It can be applicable in case of imaginary non-residential building, when the operator is curious to know the best concept of the under design building, the estimated operating cost of it and the investment cost of it in order to take appropriate decision.

As steps of the future work the following can be summarized:

- Further tests are needed in order to the validation, because only annual measured data is not enough.

- Parts of project working well, but clamp software is necessary

- Select reference buildings and modelling them in order to creating a database (e.g.: in Hajdú-Bihar region), which can be applied in energetics tender

\section{REFERENCES}

[1] M. Economidou, B. Atanasiu, C. Despret, J. Maio, I. Nolte, O. Rapf, J. Laustsen, P. Ruyssevelt, D. Staniaszek, D. Strong, S. Zinetti, Building Performance Institute Europe (BPIE) (2011, October). Europe's buildings under the microscope - A country-bycountry review of the energy performance of buildings, ISBN:9789491143014

[2] Energiaklub, „NEGAJOULE 2020“, 2011, online at: http://negajoule.eu/sites/default/files/nega_kiadvany.pdf

[3] G. Husi, P.T. Szemes, E. David, T. I. Erdei, "Building Mechatronics Research Centre as energy aware Intelligent Space", in IEEE 39th Annual Conference of the IEEE Industrial Electronics Society: IECON 2013. Vienna, Austria, 2013.11.10-2013.11.13. Piscataway: IEEE, 2013. pp. 7814-7818. (ISBN: 978-1-4799-0223-1)

[4] G. Husi, P.T. Szemes, N. Tóth, E. Dudas, "Establishment of new research infrastructure at Department of Electrical Engineering and Mechatronics, Faculty of Engineering, University of Debrecen", in Fascile of Management and Technological Engineering, Issue 1, 2013, pp. 111-116

[5] Kalmár F; Kalmár T; Csáki I; Husi G, "Interrelation between ACH and air temperature distribution in a room", In: Kwang-Woo K (szerk.) ROOMVENT 2009: Proceedings of the 11th International ROOMVENT Conference., Busan, Dél-Korea, 2009.05.24-2009.05.29., 2009. pp. 911917.

[6] Husi G: "The latest research results of the Intelligent buildings group in the DEnzero project" In: IEEE(szerk.) System Integration (SII), 2014 IEEE/SICE International Symposium. Tokyo, Japán, 2014.12.132014.12.15. [s. 1.]: IEEE, 2014. pp. 240-244. (ISBN:978-1-4799-6942-5)

[7] Jardan RK, Nagy I, Korondi P, Masada E, Nitta T, Ohsaki H., "Power generation system for utilising alternative renewable and waste energy", In: International power electronics conference. IPEC-Tokio 2000. Proceedings. Konferencia helye, ideje: Tokyo, Japán, 2000 Tokyo: IEEE, pp. 1501-1506.Vol. 3

[8] T. Csoknyai, S. Hrabovszky-Horváth, M. Seprődi-Egeresi, G. Szendrő, „National typology of residental buildings in Hungary“, 13.10.2014, 